\title{
CLINICAL OBSERVATIONS UPON THE MANCHURIAN PLAGUE EPIDEMIC, 1920-21.
}

\author{
By Drs WU LIEN TEH, J. W. H. CHUN and R. POLLITZER. \\ (Manchurian Plague Prevention Service, China.) \\ CONTENTS.

I. Introduction. Symptoms and signs of the disease
II. Note on the beginning and decline of the epidemic
III. Observations on infectivity, epidemiology and incubation period.
IV.

I. INTRODUCTION. SYMPTOMS AND SIGNS OF THE DISEASE.

Our knowledge of pneumonic plague is based upon a series of outbreaks which have occurred in recent years. The Black Death which ravaged the whole of Europe and a large part of Asia might have been plague or a virulent type of influenza such as that encountered in 1918. The famous plague of London lasting from the sixteenth to the middle of the seventeenth century was mainly of the bubonic type. Among the annual plague outbreaks happening in India since 1896, some purely localized pneumonic epidemics have been encountered among the general bubonic type. The most prominent of these occurred at Kashmir, North India, in the cold season of 1903-1904 when 1443 cases were reported with 20 recoveries (all bubonic) towards the end of the epidemic. Two small epidemies have also been seen in the Gold Coast of Africa in 1908 and 1917.

It was not until the first Manchurian outbreak occurred in 1910-11 with its huge toll of deaths $(60,000)$ that the world's attention was riveted upon this most fatal of all infectious diseases. This Pneumonic Plague was carefully studied in all its aspects by Chinese, American and Japanese physicians at the time. The Shansi epidemic of 1917-18-also purely pneumonic in character and killing 16,000 persons-furthered our knowledge of the infection. The clinical features of Pneumonic Plague are thus described by Wu Lien Teh ${ }^{1}$ :

Aetiology. Both sexes are equally susceptible and no person can withstand the disease once the organism enters the respiratory tract. Children are just as susceptible as adults, as evidenced by the Shuangchengpu cases (1911) and last Shensi epidemic (1918). The disease attacks particularly poor people because of their surroundings; but doctors, nurses, students, merchants, Europeans, Chinese, Indians, Japanese, etc., have all been attacked and succumbed.

1 Practice of Medicine in the Tropics, published in 1922 by the Oxford University Press, Vol. II. pp. 1038-46. 


\section{Observations upon the Manchurian Plague Epidemic}

Symptomatology. The incubation period is usually two to three days, but this may extend to five days. The onset of the disease is usually abrupt; prodromal symptoms are rare. The disease begins with chilly sensations, but a distinct rigor does not occur. There is headache, loss of appetite, increased pulse rate, and fever. Vomiting rarely occurs.

Progress of the case. From 24 to 36 hours after the onset, the temperature has usually risen to $103-104^{\circ} \mathrm{F} .\left(39 \cdot 4-40^{\circ} \mathrm{C}\right.$.) and the pulse rate to $110-130$ per minute. Cough and dyspnoea appear within 24 hours after the onset of symptoms. The cough is usually easy and not painful. The expectoration is at first scanty, but soon becomes more abundant. The sputum consists at first of mucus which shortly becomes blood-tinged; later it is much thinner, frothy and of a bright red colour; it now contains enormous numbers of plague bacilli in almost pure culture. The typical rusty sputum of croupous pneumonia is not observed. The conjunctivae become injected, and the tongue assumes a brown or brownish-red coat. The headache becomes worse, the expression is anxious, and the face frequently takes on a dusky hue. Labial herpes is not seen. The patient complains of pain and a restricted feeling in the chest, but this is not severe. Apart from the disturbance due to the dyspnoea and their anxiety for their condition, the patients appear to suffer little pain. In the later stages of the disease, the respirations become greatly increased and the dyspnoea is very marked, the patients gasping for breath several hours before death. Cyanosis is then common and ecchymotic spots appear in several parts of the skin, the two conditions producing a black hue and thus giving rise to the name "Black Death."

The signs of cardiac involvement are very marked in advanced cases, the pulse becoming more rapid, soft, and feeble, until finally it cannot be felt. Death results from cardiac paralysis and exhaustion. The patients sometimes succumb after slight physicalexertion, such as sitting up in bed or being moved. The temperature may decline to below normal before death. Delirium or coma is often met with before death. The urine in the later stages may show the presence of albumin. The diazo and indican reactions have not been observed in the few cases examined.

The spleen is usually not palpable, and the lymphatic glands are not enlarged. Bloody diarrhoea is occasionally observed, when $B$. pestis is found in large numbers in the stools. Leucocytosis is usually not present.

Physical signs. The physical signs in the lungs are often slight, even in cases well advanced in the disease. On percussion, dulness is often absent, and the vocal fremitus and resonance unchanged. In a small proportion of cases, however, localized areas of dulness may be distinguished. On auscultation râles are frequently not heard except shortly before death. When present early in the disease they are usually of the fine variety. Numerous râles are heard late in the disease, due to the oedematous condition of the lungs. Feeble respiratory sounds or pure tubular respiration over small areas are commonly heard. Not infrequently a dry pleuritic rub is heard at the side of the chest.

The heart is usually dilated on the right side, but not greatly. The heart sounds are fast and become feeble towards the end. In the early stage the second pulmonary sound may be accentuated, but this character is soon lost.

Complications and Sequelae. Pulmonary plague always ends in death with general signs of septicaemia caused by the $B$. pestis. The progress is very rapid, death usually taking place in two to three days from the onset of symptoms. 


\section{W. L. Teh, J. W. H. Chun and R. Pollitzer}

Diagnosis. The diagnosis of pulmonary plague is usually clear from the bacteriological examination of the sputum in which the bacillus is found in enormous numbers and in almost pure culture. A rise in temperature and an increased pulse rate are sometimes the only early symptoms noticed, and before the characteristic sputum appears the diagnosis may be doubtful, especially at the commencement of an epidemic or in isolated cases. However, the blood should always be examined microscopically and culturally, as the case may be one of primary septicaemia. A bacteriological diagnosis is the only certain method for excluding pneumonic infection due to organisms other than $B$. pestis, though the absence of clear physical signs in the lungs ought to suggest plague infection. As has been said above, coarse sibilant sounds and râles are seldom heard in plague pneumonia.

The sputum in plague is not purulent but of a thin, frothy, pink, or red nature. The cough is generally not so troublesome as in croupous pneumonia. The duration of the disease is usually less than two days, and many cases succumb within 16 hours from the onset of symptoms. Cases may last three, sometimes four days, but rarely more.

Differential Diagnosis. Pulmonary plague has to be differentiated from typhus exanthematicus, ordinary croupous or broncho-pneumonia, relapsing fever, and influenzal pneumonia. The extraordinary virulence of the recent epidemic of influenza (1918), in which such a large proportion of pneumonia complications occurred with symptoms and signs unusually like those of pulmonary plague, has suggested to some observers the possibility of the causative organism being an attenuated form of $B$. pestis. But whereas in pneumonic plague $B$. pestis exists always in enormous numbers in the sputum, in influenza pneumonia a large variety of organisms, with or without Pfeiffer's bacillus, are present, but never $B$. pestis.

Prognosis. The prognosis is wellnigh hopeless, as no authentic case of pulmonary plague in either of the two great epidemics has been known to survive.

Treatment. This is also not satisfactory, and the best that can be done for a patient is to allay his sufferings. As soon as a case is diagnosed, the patient should be forthwith isolated, preferably in a hospital built for the purpose, and the contacts kept under observation. In Manchuria and Shansi, owing to the primitive conditions of living and to the conservative ideas of the inhabitants, it was most difficult to adopt strict quarantine measures. In an epidemic, unless the local police authorities are placed under the control of the trained sanitary officers, leakages in the organization are bound to occur and the infection spreads unnecessarily. Capitalistic interests, official dignity, and medical efficiency are often at loggerheads on such occasions. The only remedy appears to be education, not only of the poor but also of the educated classes, in matters of quarantine and sanitation. In the Shansi epidemic, Young allowed the contacts to remain isolated in their own compounds, while the plague patient was removed to hospital. Each individual was taught to use a gauze mask, and although in some cases whole families were wiped out one after the other, the people were kept calm and learnt elementary measires of precaution. Any harsher measure would have produced riots. In the Manchurian epidemic, 1911, although much opposition was experienced at first, the people followed the advice of the sanitary officers, even to the extent of permitting 6000 bodies to be cremated in Fuchiatien alone. As a result of the successful measures in this city other cities followed suit, and cremated their own dead even when no medical officer was in charge. 


\section{Observations upon the Manchurian Plague Epidemic}

Prophylaxis. General. Apart from personal care, the strictest attention should be devoted to the adoption of general sanitary measures. On removal of a plague patient, his bedding should be collected and sterilized, preferably by steam or, if this be unavailable, in a solution of cresol or izal. The room and furniture should be disinfected in the usual way. All cups and small articles likely to have been grossly contaminated with sputum should be boiled. In case of death, especially in winter, when the ground may be frozen to a depth of seven feet, the bodies may be confined in coffins and sent to a prepared pit for cremation along with others. This method, wherever available, is the most economical and efficient, and prevents the possibility of the bodies being gnawed by rats and thus leading to a bubonic epidemic. The management of an epidemic of pulmonary plague depends much upon the locality and upon the nature of the inhabitants. Where the people are educated to these necessary measures, as in Suffolk (1918), the outbreak should be at once suppressed, but in distant provinces in China, where the masses are not yet ripe for preventive medicine, considerable opposition may be expected. Wherever possible, the full co-operation of the local authorities should be obtained by the sanitary officers in charge.

Personal. No vaccine or serum discovered has yet been successful in immunizing a person against plague pneumonia. Hence, those in attendance upon the suspected and sick, such as sanitary officers, hospital assistants, stretcher coolies, disinfection staff, are advised to wear a proper mask as recommended by the Mukden Conference. There is no need to apply any deodorant or antiseptic to this mask, as its protective properties are entirely mechanical.

\section{NOTE ON THE BEGINNING AND DECLINE OF THE EPIDEMIC.}

So far as we can ascertain, pneumonic plague epidemics have arisen as the result of earlier bubonic infections, which develop lung symptoms. These cases cough up masses of plague bacilli in the sputum, and under suitable circumstances such as overcrowding, winter weather, proper humidity, and indiscriminate spitting, infect others by the droplet method. Isolated instances of pneumonic plague arising in a laboratory have been recorded ${ }^{1.2}$. Simpson observed on several occasions "the first in a series of pneumonic cases occurring in an infected locality, the first generally arising in a house in which a large number of rats have died." Two interesting examples of pneumonic plague occurring on board steamers were found in the case of (1) British mail steamer Nagoya, which had eight deaths out of a crew of 195 in 1919 and (2) British freighter Friary, which lost 8 lascars out of a crew of 21 in 1901.

Although no bubonic cases appear to have been observed immediately before the 1910-11 outbreak, it is very probable that it originated in this manner inasmuch as in the years preceding the epidemic sporadic cases of bubonic plague alternated with pneumonic cases in the epidemic centres of Transbaikalia and Kirghiz steppes ${ }^{3}$.

1 Poech, Ueber die Beulenpest in Bombay im Jahre 1897, I.

2 Mededeelingen van den Burg. Geneesk. Dienst in Nederlandsch-Indie, 1916, v. 1.

3 Wu Lien Teh, r. c. p. 1038. 
From the 1921 epidemic we have been able to establish a complete link in the chain of evidence so far as human cases are concerned. Bubonic cases occurred in Transbaikalia in the late summer of 1920. Besides some cases at Kailastu (70 versts west of Manchouli) four were reported in September from Abagatui (Mongolia, 8 versts from Manchouli) and three from Dauria (60 versts west of Manchouli). Two Cossack soldiers were infected by the Abagatui cases and died, the last on the 20th September. After this no more was heard until October when plague was reported at Hailar. Most of the Hailar cases were observed by us. They are tabulated in Tables I and II. These cases are described under another heading of this report.

After the bubonic cases, a series of the septicaemic variety were met, leading later on to the purely pneumonic ones. The slow rate of increase in the number of cases from October to end of November was characteristic, and this differed markedly from the rapid spread in other places as soon as the pneumonic type was fully developed.

What then is the reason for this change in the character of the epidemic? In India, as we all know, occasional instances of pneumonic plague were seen among a large majority of bubonic cases, but these rarely developed into an epidemic. In Siberia, Mongolia, Manchuria and Shansi, on the other hand, the early bubonic cases showed a tendency to assume the pneumonic form, and although extensive outbreaks were comparatively infrequent (in Manchuria only two epidemics in ten years) the danger of a pneumonic outbreak succeeding the bubonic infections has always to be borne in mind.

Barber and Teague ${ }^{1}$ tried by experiments with $V$. cholera, Sarcina and $B$. prodigiosus to elucidate this phenomenon.

In their opinion the bacilli of pneumonic plague sputum were enabled to persist longer in an atmosphere with a low water deficit, such as is met with in the crowded inns of Manchuria in the winter. Hence the longer these droplets persisted, the greater would be the danger to the inmates. The Manchurian climate with a temperature considerably below zero C. fulfilled these conditions, and was therefore largely responsible for the propagation of the disease which would not happen in a warm country.

While ready to admit a cold climate as an important factor in the spread of pneumonic plague, we are not sure that the propagation of the disease is entirely due to this water deficit. It is possible that the origin of the Manchurian attacks can be traced to plague among marmots and not to an epizootic among rats. In this connection, it may be profitable to remember a statement made by $\mathrm{McCoy}^{2}$ that "Pneumonic plague in man rarely occurs from rat infections and it is an interesting and possibly significant fact that in plague squirrels there is a very definite tendency to pulmonary localisation, a condition which never occurs in plague rats." At the same time, the peculiar way in which the Hailar cases developed in 1920 strongly suggests a rat-flea infection.

I Phil. Journal of Sc. Vol. vII. Sec. b, No. 3, p. 157.

2 Am. Journ. Hyg. I. No. 2. 


\section{Observations upon the Manchurian Plague Epidemic}

Before discussing the decline of the epidemic it is necessary to review the observations made on the virulence of the $B$. pestis in pneumonic plague. At the time of the Mukden Conference, experiments comparing the virulence of bubonic strains with those recently isolated during the pneumonic epidemic were made, and led to the conclusion that the $B$. pestis in pneumonic plague possesses a higher virulence than many of the bubonic strains tested. Strong observed further that there was a tendency to marked stability in the virulence of the $B$. pestis. Others contended that a longer incubation period was noticed towards the end of the epidemic, but these observations were probably not reliable $^{1}$ and experimental evidence showed the virulence at the end of the epidemic to be undiminished ${ }^{2}$.

Thus when the question of a spontaneous decline of the epidemic was raised it was evident that this supposed phenomenon could not be traced to a lessened virulence of the $B$. pestis. All observers agreed that, even if there should exist a spontaneous decline of the epidemic, the preventive measures were of the utmost importance in restricting the number of cases during the prevalence of the epidemic. Most of those taking part in this discussion were even of opinion that the preventive measures alone were responsible for the termination and denied the possibility of a spontaneous decline. On the other hand, some stress was laid on the possible influence of meteorological factors upon the course of the epidemic. The Conference thus decided ${ }^{3}$ :

The chief factor in the decline of the epidemic has probably been the preventive measures which were enforced, either in accordance with scientific methods or by the crude efforts of the people to protect themselves. Climatic influences may have contributed indirectly, or even directly, toward bringing the epidemic to an end, but the evidence presented on these points is inconclusive. The decline has not been due to any loss of virulence of the bacillus.

As shown in our paper on the postmortem findings of 1921 we found one factor which might possibly play an important role in the decline of the epidemic. This was the prevalence of pneumonic cases at the height of the epidemic as compared with their scarcity towards the end, at which period only pulmonary cases prevailed. These were far less infectious, because of the absence of sputum, than the strictly pneumonic. Being thus rendered less infectious, the "spontaneous decline" of the epidemic, even in foci unattended by sanitary organisations, might be easily explained.

\section{OBSERVATIONS ON INFECTIVITY, EPIDEMIOLOGY AND INCUBATION PERIOD.}

In these epidemiological and clinical notes only such observations will be mentioned which seemed rare in former outbreaks or not mentioned at all.

Instances were seen where contacts had been certainly exposed to infection and yet remained healthy. Chun ${ }^{4}$ mentioned the fact that many patients

\footnotetext{
1 Mukden Report, pp. 73-74.

2 Ibid. pp. 55, 75.

3 Ibid. p. 389.

" "Salient Points about the Recent Pneumonic Plague in Harbin."
} 
suffering from ordinary diseases were sent to the hospital as plague cases. It was impossible for the inspection squads to be always right in their prima vista diagnosis, especially with the Russian squads in the Railway area where they had great difficulty in ascertaining the history of the sick.

So, instead of taking the risk of leaving the possible plague patients in their homes, they sent many "suspects" to the hospital where special wards were provided for them. On admission every precaution was taken by us to separate the real plague cases from the suspects, and as for the patients who suffered from ordinary diseases we made a point of sending them home whenever possible.

In spite of the exercise of much care, it happened that patients suffering from ordinary diseases did sometimes stay in the plague wards during the 1921 epidemic, as some did in the 1911 outbreak $^{1}$.

(a) A man, age 26, was admitted into the plague ward, because he expectorated sanguinous sputum, and remained there eight days. During this period, three plague patients were put in the same ward and died. Further investigation into his case revealed the fact that he was really suffering from croupous pneumonia. Two animals were injected with his sputum and they both died, showing only pneumococci in their organs. This patient made a good recovery afterwards.

(b) Three Chinese from Irkutsk were admitted into the plague ward. They were starving refugees. They had passed through the plague infected region on their way to Harbin and were thought to be suffering from plague. One of them did die of plague soon after admission, the second man died of inanition, but the third man, named An, did not die after spending 11 days in the ward. This man was particularly interesting, because he volunteered to work as ward attendant and after a few weeks' duty, was infected with plague and died. So one could not consider him as naturally immune because he did not at first "catch" plague during his stay as a patient in the ward.

In connection with first case (a) the possibility of the protection afforded by a pneumococcal infection against plague has to be considered ${ }^{2}$. We accidentally came across some apparent evidence to support this when injecting rabbits with plague cultures contaminated with diplococcus lanceolatus. The rabbits died quickly, but at the P.M. only pneumococci could be recovered. A very interesting instance was observed in Dalainor. On 6th February, three plague corpses were discovered under a bench in an opium den kept by a Japanese woman. The owner and sixteen men who were found smoking in the den were all removed to the isolation wagons, but none of them subsequently suffered from plague.

Dr Hsieh, in his report on these cases, remarked that the local people believed that opium smokers were immune to plague.

Of course, there is no evidence that this belief is justified and so one may put it in the same category as the supposed prophylactic use of alcohol against cholera.

$$
{ }^{1} \text { Mukden Report, p. } 295 . \quad 2 \text { Ibid. p. } 1557-8 .
$$




\section{Observations upon the Manchurian Plague Epidemic}

On the contrary we may mention that while conducting P.M. examinations, we noticed many plague corpses with morphine-injection marks. As in the previous epidemic ${ }^{1}$ we also observed instances where people attended on their sick relatives and yet did not become infected. A woman, aged 24, looked after two plague stricken relatives and when they died, she attended on her father. Because she had fever (afterwards found to be due to an alveolar abscess) she and her father were admitted into the same room in the suspect ward. On the next day, her father died of pneumonic plague. She herself recovered from her abscess three days later and was sent home after a further period of five days.

We found that in several instances children escaped infection while the rest of their family succumbed to plague.

(1) In Shwang Cheng Pu, 13 members of a family living in a compound died within two weeks, leaving a child one year old.

(2) In Harbin, a boy of 11 remained well while six members of the same household died within two days.

(3), (4) In the hospital we had two lots of children who did not become infected, though their mothers died.

We can only cite these cases ${ }^{2}$ as curious and lucky escapes and cannot deduce therefrom evidence of immunity of children from plague. Out of 3412 prostitutes in Fuchiatien, only 12 deaths from plague were reported. Twelve servants (men) also died. The brothels were closed for one month at the beginning of the epidemic but were reopened later on, and some deaths among the guests were reported.

The theatres were also closed at the beginning, but some of them were reopened. Several cases of plague occurred among the stage people living on the premises.

Four instances are recorded of plague patients suffering from fever and cough travelling in crowded railway cars on the Harbin-Changchun line (150 miles). On 2nd February, a dying man with haemoptysis was found on the train at Yaomen. The other 47 passengers were sent on to Harbin for observation, but as they remained healthy after six days, they were liberated. On 16th, 20th Feb. and 15th March, 37, 47 and 30 passengers respectively travelled on each occasion with a sick man but no one developed plague subsequently. Jasienshi ${ }^{\mathbf{3}}$ reported a similar instance in the previous epidemic.

In contrast to the above, we may cite a few interesting cases of infection by contact.

A prisoner (convicted for theft) developed plague after two days' confinement and was sent to the hospital where he died. Three days later five other prisoners from the same cell died of plague.

In an iron foundry, a man died of plague. To avoid inconvenience, the owner jnduced a military sergeant to rush the body to the burial ground without notifying the police. Soon after eight persons including the owner
1 Mukden Report, p. 232.
Ibid. p. 172.
s Ibid. p. 220. 
died, one after another. Three remaining contacts (including the owner's brother) were sent to the isolation wagons.

In a Cold Storage Company, a fitter visited his father who was ill with plague in the city. After his father's death, he induced four friends, who were living with the other labourers of the company, to carry out the corpse and deposit it in the street. The next day he developed plague and on the day after that his four friends were also plague stricken. They all died in the hospital 48 hours after admission. Meanwhile other cases occurred in the labourer's house and the contacts ran away to different places. One of the fugitives infected a household of 12 persons.

Sanitary squads and burial-ground personnel. All available data from Harbin and Dalainor are tabulated in Tables III and IV.

The mortality among the sanitary squads was high especially in Dalainor where it reached 50 per cent., the highest figure reported in the previous epidemic ${ }^{1}$.

When comparing this high mortality among the sanitary coolies and the clear record among our dressers, one must bear in mind the fact that the coolies were certainly more exposed to infection than the dressers. Moreover, the dressers were more aware of the danger and took care to follow the precautionary measures exactly.

To account for the high percentage of infection among the sanitary coolies and sanitary police one more factor has to be considered, namely the stealing of money and clothes belonging to the sick and dead. Thus two of the coolies and one policeman were known to have committed thefts of this nature in the plague wards at night time. As they died soon afterwards of plague, we may say that some indirect evidence of the infectivity of the clothes and money is established.

This factor also deserves notice when we consider the high mortality of the burial-ground coolies in Harbin. In Dalainor, however, Dr Hsieh did not find any plague deaths among the burial-ground coolies, although they undoubtedly committed thefts.

Incubation period. The average incubation period was three days, varying from two to five days. Longer periods were also observed as in the previous epidemic. Thus:

(1) One man was sent from the isolation wagons to the suspect ward because he had fever. He had continuous fever for seven days, but repeated examinations of his non-sanguinous sputum proved negative, until the seventh day when he showed $B$. pestis and blood in his sputum.

(2) A case was reported from Asheho of a man dying eight days after the death of his wife.

(3) A woman, aged 17, was sent to the isolation wagon after the death of her husband. For six days she had a normal temperature. Before going home, she had a bath. She then felt ill and giddy but was able to walk home, a distance of half a mile. Soon after she became very ill and was admitted into 1 Mukden Report. p. 194. 


\section{Observations upon the Manchurian Plague Epidemic}

our hospital six hours later. On admission she had no cough or expectoration. But on the next morning blood and $B$. pestis were found in her sputum and death occurred 24 hours later. Post-mortem examination (No. 6) revealed plague pneumonia.

\section{NOTES ON SYMPTOMOLOGY AND THERAPY.}

(a) Non-infective period at beginning of disease.

We can say without hesitation that as a rule there is a non-infective period of about 24 hours during which the patient has fever and quick pulse but no cough or bloody expectoration. This is the time when he may be moved to hospital without danger to others.

As an illustration, Dr Yuan Teh Mao, chief of the inspection squad, felt a little unwell on the morning of the 5th day after infection. He was on duty nevertheless, attended a meeting of 26 people in the afternoon and mixed with the other members of the staff for the whole day. In the evening, he went to bed with fever $102^{\circ} \mathrm{F}$. Next morning, he had a little cough and $B$. pestis and blood were found in his sputum. None of the 60 persons with whom he came in contact on the previous day became infected.

Chung ${ }^{1}$ reported a similar instance (case of a Japanese doctor).

Zabolotny ${ }^{2}$ remarked on this non-infective period which he estimated as two days.

(b) Observations upon cough and haemoptysis.

The cough of the plague patient is at first dry, but very soon he expectorates a liquid, frothy and bright red sputum. Frequently, there is a considerable amount of bloody sputum, especially among young patients, so that the floor and bedding are covered with blood. For instance, a patient was able to spit into 12 Petri dishes within a few minutes and was still coughing and spitting afterwards. Sometimes profuse haemorrhage was observed immediately before death.

Epistaxis was not observed. Bloody froth was often seen at the nostrils of patients in extremis and corpses.

Cases with no cough or sputum will be mentioned later on.

(c) Pain.

There is not much pain in connection with plague pneumonia, in contrast to ordinary pleuro-pneumonia, though a few exceptions were observed. Nearing death, the patient is very short of breath, mildly delirious, often tries to sit up or struggles to go out into the open air. He is not conscious of much pain owing to $\mathrm{CO}_{2}$ intoxication and incipient oedema of the brain. Some cases in Manchouli kept cheerful in spite of alarmingly profuse haemorrhagic expectoration.

Active delirium is rare. This may be due to the gentle and stoical nature of the patients who are mostly coolies and are not addicted to alcohol.

$$
1 \text { Mukden Report, p. } 226 . \quad 2 \text { Ibid. p. } 91 .
$$


(d) Symptoms of in-coordination.

The loss of coordination of the voluntary muscles of the legs together with other nervous symptoms render the plague patient unsteady in his gait. To the uninitiated, he resembles a drunken man and several drunkards have been sent into the hospital as possible plague cases.

This staggering gait has not been explained on anatomical grounds. Simpson" ascribed this symptom "to a progressively intoxicating effect of the plague on the nervous system." Our records mention the following:

(1) A man, aged 24, on admission into the hospital, stumbled on to a long wooden stool and fell head first, almost turning a somersault. After lying on the ground for five minutes he got up with great effort and sat on the stool, still unable to hold his head up. He rested on another patient lying on the stool next to him.

He could not answer questions. His knee-jerks were not exaggerated and as far as one could judge, he had no nystagmus. He died half an hour afterwards with increasing dyspnoea and cyanosis. At the P.M. (No. 16) the meninges were found to be congested and the brain oedematous. The petrous portion of the temporal bone was removed for further examination.

(2) Another man was closely observed. He could walk, though unsteadily, to the ward. After five minutes, he wished to come out, but was now able to walk only with assistance. He evidently felt giddy for he held on to the drain-pipe for three minutes. Then he fell down gasping and died after eight minutes.

\section{(e) Clinical observations upon urine and faeces.}

Only little attention was directed towards the urine and faeces of plague patients in the previous epidemic. Kasol examined six samples of urine. He found them clear or slightly cloudy, acid in reaction, and with a specific gravity of 1024-34. Albumen was found in two out of the six. Diazo reaction, indican, sugar and blood tests were negative.

A systematic analysis of 30 urines was conducted by Chun (see Tabulation No. VI). It is interesting to note that the chlorides were diminished in all cases, a feature usually found in ordinary pneumonia, bubonic plague $\mathrm{e}^{2,3}$ and other fevers. The absence of blood is noteworthy. Other findings corresponded with those changes met with in acute febrile diseases. No case of intestinal infection was observed, in contrast to clinical reports on cases during the previous epidemic ${ }^{4}$. At the P.M. (No. 12) of a young subject (age 10) liquid faeces were seen flowing out of the rectum. The mesenteric glands were enlarged as usual. Nothing abnormal was detected in the alimentary canal. Cultures of $B$. pestis were obtained from the ileum and colon as in other cases.

1 A Treatise on Plague, p. 267.

3 Jennings, Manual of Plague, p. 89.
I Ibid. p. 292.

4 Mukden Report, pp. 165, 183. 


\section{Observations upon the Manchurian Plague Epidemic}

\section{(f) Duration of disease.}

Tabulation showing duration of stay of plague patients in hospital:

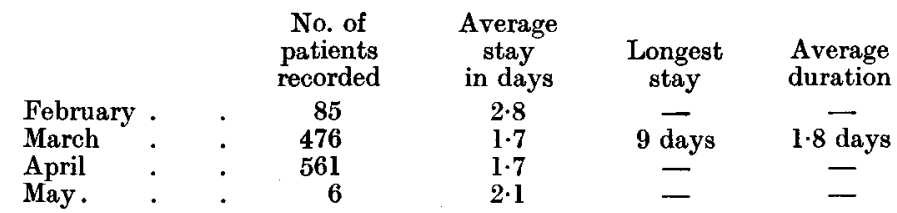

In the majority of cases, patients were sent into the hospital within a few hours of their illness. So the above average duration, 1.8 days, may well be taken as the duration of the illness, and corresponds with those findings of Kasai $^{1}$ and Strong ${ }^{2}$. It is 24 hours longer than what Heffkine ${ }^{3}$ found in Harbin Jan. 1911 however. Emphasis must be laid on the fact that the average duration of illness towards the end of the epidemic (April and May) was no longer than at the beginning-another proof that the virulence of $B$. pestis was in no wise diminished.

Kasai (loc. cit.) recorded a few instances where the patients survived five to seven days. We were able to observe a case of nine days. A man, age 32 (P.M. No. 11), came to the hospital voluntarily on the 16th March. After admission, he had fever continuously, $102^{\circ} \mathrm{F}$., feeble pulse and $B$. pestis and blood in his sputum. His sputum assumed a muco-purulent and rusty red appearance during the later stages, though numerous $B$. pestis were present. On the 23rd March a flask of $B$. subtilis emulsion was injected subcutaneously with some apparent benefit. On the morning of the 24 th, he was semi-conscious though he could be roused. Towards noon, he became stertorous and died half an hour later of heart failure.

At P.M., broncho-pneumonia was found in four lobes; no other unusual features were present, except an anaemic infarct in spleen which was the only one found in our P.M. examinations.

(g) Cases of children.

A few cases of plague among children and women came under our notice. Economic conditions force the coolies to migrate from Shangtung and Chihli to Manchuria leaving their womenfolk and children behind, and to live in crowded lodgings. These factors account for the high percentage of coolies among our patients and the small percentage of women and children.

Both clinical and P.M. observations show that the children succumbed to plague more easily and quickly than adults. For, out of six P.M. examinations of children only two had well marked pneumonic changes. One pulmonary case was seen at the height of the epidemic, two had slight pneumonic changes, and one had a single patch of pneumonia. The case of a still-born foetus is fully described in the P.M. article.
1 Mukden Report, p. 177-178.
2 Ibid. p. 431.
3 Ibid. p. 106. 
(h) Non-pneumonic cases in 1921 epidemic.

(i) Bubonic. We have seen the series of bubonic cases beginning with those at Abagatui (August), Kailastu and Dauria (September). One of the Abagatui cases was treated at Manchouli Hospital and recovered. Two Cossacks infected by this family developed buboes and died (the last on September 20th). Out of the possible thirteen, only one recovered.

Then came the Hailar cases, numbering at least eleven, the earliest ones, as in the previous thirteen, being entirely among Russians. Throughout the epidemic, which now assumed a pneumonic character, we were on the look-out for further bubonic cases, but the following were the only ones recorded in this series:

(1) One doubtful bubo in a Russian man from the Priamur district treated at Suifenho. This patient died on 9th March.

(2) One bubonic case reported in February by a Russian lady physician of Chita as occurring among 22 cases at six cities in Transbaikalia.

(3) One bubo in right groin of a Russian woman Bulak, aged 25, pregnant four months. We saw this patient on April 5th and following days. Patient was married and lived in a small house in Pristan doing her own household work. In the same compound some Chinese were living, but no plague cases had so far been reported there. On March 3lst she experienced a prick in right foot and noticed a small swelling in the groin next morning (April 1st) with fever. When admitted on April 4th, both right femoral and right inguinal glands were swollen, each of size of walnut. Dr Askanoff of the Railway Hospital punctured the femoral bubo and noticed a few definite $B$. pestis in the smears (15 B. pestis on one slide). Cultivations and animal experiments with guinea-pigs gave positive results for $B$. pestis. Bubonic plague was therefore diagnosed. On the day of our examination (April 5th), there was considerable swelling, the inguinal bubo measuring size of a small apple, and the femoral slightly smaller. Both swellings were painful and tender. Ichthyol was applied to the region. 240 c.c. anti-pest serum (Japan) was injected on April 4th, and repeated next day. There was marked induration at site. Patient looked flushed but not very ill. Temperature undulated about 39.5 for some days. The swelling gradually disappeared with fall of temperature and patient eventually recovered. A healthy full-time baby was born subsequently.

(4) A Russian man was admitted into Manchouli Hospital on May 26th with a marked right submaxillary bubo. He had no cough or sputum. He looked very ill and had high temperature. He died on May 29th after four days illness.

(5) Out of 469 cases of plague at Vladivostok all were pneumonic except one Russian with a right inguinal bubo, who was admitted on July 10th and died two days later. About this time systematic rat-examinations showed two positive rat infections on July 2 nd, and again five between July 18th to 23rd.

(6) Murakami (Japanese military surgeon) also reported a doubtful bubonic case in Vladivostock on August 10th.

Of those six cases-all in Russians-two were doubtful, two were in right limb, one was in submaxillary region while the location of the sixth 


\section{Observations upon the Manchurian Plague Epidemic}

(Transbaikal) one was not stated. The only case we have full data of, was that of the Russian woman, who was seen in hospital four days after the alleged prick. If the swelling was due to this prick as she believed, it must have developed unusually quickly for an ordinary septic infection. But a scratch due to fleas might easily have been mistaken for a prick. It is likely that the mode of entry of the $B$. pestis in her case was not dissimilar to that of any other bubonic case, namely through a rat flea. The fact that no other case of plague-either pneumonic or bubonic-occurred in the same compound tended to support this theory of a stray infection.

Should any accidental sputum touch the abrased skin of a hand, the bubo would then appear in the arm, which none of our cases showed. Still the mystery remains as to the appearance of the rare instances of bubonic plague among thousands of pneumonic cases seen. We have no explanation to offer as to their actual cause. It is noteworthy, that no cases of bubonic plague developed towards the end of 1921 epidemic as in the case of Kashmir.

(ii) Pulmonary cases. In two separate articles we have drawn attention to the occurrence of strictly pulmonary cases towards the end of epidemic. Cases apparently similar to these pulmonary ones were met with at postmortems during (not end of) the epidemic of 1910-11. Similar clinical observations were made at that time. Christie maintained that "septicaemic" cases were comparatively frequent and formed about 10 per cent. of all cases; however, owing to the rapid death in this type of the disease very few patients died in the hospitals. Hill after examining the rough clinical records of 15,000 cases in 1911 said "the septicaemic cases without pneumonia constituted a very small proportion of the whole, probably about 1 per cent. or less."

Our own observations tended to confirm this rare occurrence of the pulmonary type at the height of the epidemic. It is true that at this time our autopsies were mostly performed on cases which had been observed clinically and not on cadavers picked up in the streets, but there is no evidence to prove that the latter street corpses had succumbed to the type described by Christie. According to our observations most of these cases had been sick and died inside the houses and were then thrown out in order to avoid isolation of the rest of the household. It is interesting to recall P.M. 17 (child of one year) found dead in the street at beginning of April, and showing not the pulmonary but slight pneumonic changes. Should any further occasion arise, it might be wise for investigations to be directed upon these street corpses during the height of the epidemic.

In our records we found seven instances where patients died suddenly without apparent signs of pneumonia. One of these may be mentioned here. A girl aged 3 years (No. 4 of our P.M. series) was admitted as a contact on March 4th because her mother was suffering from plague. A swab taken from the throat of the child showed pneumococci in smears and thin gram negative bacilli; in cultures, Micrococcus catarrhalis and a few bipolar-stained gram negative suspicious bacteria. The child was placed on March 4th under the care 
of ap elderly woman, who however became ill on March 5th and died the same evening. The child was then placed under the care of two men convalescent from typhoid. She looked well and bright the whole day of March 5th and had no cough or bloody expectoration. She died early on March 6th. At P.M. slight changes in larynx and trachea and slight pneumonic changes in lungs were found (Group B of our cases). Thus this case cannot be considered as pulmonary in the strictest sense of the word, but belongs to the same category as Case 17 mentioned above. Similar cases were met with in our experience where patients died suddenly from apparent pneumonia and did not show cough with bloody expectoration until immediately before death.

\section{(i) Therapeutic measures.}

No form of treatment was found of any avail. However, mention should be made of several attempts to save the lives of our plague patients. No effort was spared in trying to help Dr Yuan, our able colleague, and others of our staff who were infected in the course of their duty.

Names of the therapeutic agents used were:

(1) Anti-plague serum (Japanese source) 40-80 c.c. (repeated several times) both intravenously and hypodermically.

(2) Methylene blue by the mouth.

(3) Eusol 20-120 c.c. intravenously.

(4) Formalin solution (1-200 strength) 100-200 c.c. intravenously.

(5) Neoarsenobenzol 0.4-0.9 grm. intravenously.

(6) Sod. gynocardate 2 c.c. of 1 per cent. solution intravenously.

(7) B. subtilis emulsion 25 c.c.

(8) B.H. emulsion 25 c.c.

(9) Electrargol 10 c.c. hypodermically.

Some of the drugs were given as soon as the diagnosis was reasonably sure. As reported, they did not cure the patient, nor did they prolong life. On the other hand, drugs such as neoarsenobenzol, eusol and sod. gynocardate appeared to hasten death, as the patients generally died within 24 hours.

\section{TABLES I-VI.}

Table I. Early bubonic plague cases observed at the beginning of the epidemic in Hailar.

\begin{tabular}{|c|c|c|c|c|c|c|}
\hline No. & Case & Residence & $\begin{array}{l}\text { Date } \\
\text { taken } \\
\text { sick }\end{array}$ & $\begin{array}{c}\text { Date } \\
\text { admitted } \\
\text { to hospital }\end{array}$ & $\begin{array}{c}\text { Date } \\
\text { of death }\end{array}$ & Observations \\
\hline 1 & Mrs Tarelkin (Russ.) & $\begin{array}{c}\text { Railway bridge } \\
\text { barrack }\end{array}$ & Oct. 22nd & - & Oct. 23rd & $\begin{array}{l}\text { Fever, angina, } \\
\text { swollen neck, } \\
\text { rigor }\end{array}$ \\
\hline 2 & $\begin{array}{l}\text { Son of Mrs Tarelkin } \\
\text { (Russ. aet. 9) }\end{array}$ & $"$ & $"$ & - & ", & $\begin{array}{l}\text { Fever, swollen neck. } \\
\text { (Was seen by } \\
\text { Russ. Hospital } \\
\text { Feloher) }\end{array}$ \\
\hline 3 & $\begin{array}{l}\text { Soldier Chen } \\
\quad \text { (Chinese aet. 24) }\end{array}$ & ", & Oct. 23rd & - & Oct. 25th & $\begin{array}{l}\text { Fever, swollen neck, } \\
\text { rash on body }\end{array}$ \\
\hline
\end{tabular}




\section{Observations upon the Manchurian Plague Epidemic}

\begin{tabular}{|c|c|c|c|c|c|c|}
\hline \multirow[b]{2}{*}{ No. } & \multicolumn{4}{|c|}{ Table I continued } & & \\
\hline & Case & Residence & $\begin{array}{l}\text { Date } \\
\text { taken } \\
\text { sick }\end{array}$ & $\begin{array}{l}\text { Date } \\
\text { admitted } \\
\text { to hospital }\end{array}$ & $\begin{array}{c}\text { Date } \\
\text { of death }\end{array}$ & Observations \\
\hline 4 & $\begin{array}{l}\text { Son of Mrs Tarel kin } \\
\text { (Russ. aet. 16) }\end{array}$ & $\begin{array}{c}\text { Railway bridge } \\
\text { barrack }\end{array}$ & Nov. 15th & Nov. 15th & Nov. 17th & $\begin{array}{l}\text { T. } 40^{\circ} \text {, rash on body, } \\
\text { small, ill defined } \\
\text { buboes. Autopsy }\end{array}$ \\
\hline 5 & $\begin{array}{l}\text { Son of Mrs Tarelkin } \\
\text { (Russ. aet. 18) }\end{array}$ & "' & " & " & Nov. 21st & $\begin{array}{l}\text { T. } 38^{\circ} \text {, bubo left } \\
\text { groin. Autopsy }\end{array}$ \\
\hline 6 & $\begin{array}{l}\text { Soldier Chang } \\
\quad \text { (Chinese aet. 19) }\end{array}$ & ", & Nov. 17th & 一 & Nov. 19th & Bubo left arm-pit \\
\hline 7 & $\begin{array}{l}\text { Mr Tarelkin } \\
\text { (Russ. aet. 43) }\end{array}$ & ", & Nov. 18th & Nov. 18th & - & $\begin{array}{l}\text { Bubo left groin- } \\
\text { recovery. (See } \\
\text { Table II) }\end{array}$ \\
\hline 8 & $\begin{array}{l}\text { Soldier Chao } \\
\quad \text { (Chinese aet. 21) }\end{array}$ & ", & Nov. 21st & Nov. 24th & Nov. 24th & $\begin{array}{l}\text { Fever, bubo left } \\
\text { axilla }\end{array}$ \\
\hline 9 & Chinese coolie & Yi Shun Tien & $?$ & $?$ & Nov. 13th & Septic (? bubo) \\
\hline 10 & Chinese coolie Wang & Yu Tai Chan & $?$ & $?$ & Dec. 2nd & Septic (? bubo) \\
\hline 11 & Chinese coolie, Han & Soldier's inn & $?$ & $?$ & Dec. 8th & Septic (? bubo) \\
\hline
\end{tabular}

Table II.

Name. Tarelkin (Russian male). Age 43. Disease, Bubonic P. (left femora). Cured.

\begin{tabular}{|c|c|c|c|c|c|c|c|c|c|c|c|c|c|c|c|c|c|c|c|c|c|c|c|c|c|c|c|c|}
\hline Time & M & & M & E & $\mathrm{M}$ & $E$ & $M$ & E & & $E$ & $\mathbf{M}$ & $E$ & $\mathrm{M}$ & $E$ & M & $E$ & $M$ & $E$ & M & $E$ & $\mathrm{M}$ & $E$ & $M \backslash E$ & & $M$ & E & & $E$ \\
\hline Nor. & & 9 & 2 & & 2 & & 22 & & 23 & & 2 & 4 & 25 & & 26 & & 27 & & 2 & & 2 & & 30 & & Dec & & 2 & \\
\hline \multirow{7}{*}{$\begin{array}{l}\text { Fahr } \\
107^{\circ}\end{array}$} & & & & & & & & & & & & & & & & & & & & & & & & & & & & \\
\hline & & & $\ldots$ & - & & & & & & & & & & & & & & & & & $\ldots$ & & & & & & & \\
\hline & & & & & & & & & & & & & & & & 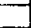 & & & & & & 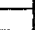 & 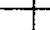 & & & - & & \\
\hline & & & & & & & & & & & & & & & & $\therefore$ & & & & & & & & & & & & \\
\hline & & & $\therefore$ & & & & & & & & & & & & 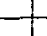 & - & & & & & 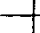 & & 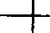 & & & & & \\
\hline & & & & & & & & & & & & & & & 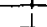 & 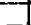 & - & & & & - & & 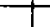 & & & & & \\
\hline & & & & & & & & & & & & & & & - & 7 & - & & & & & & 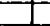 & & & & & \\
\hline \multirow{3}{*}{$106^{\circ}$} & & & ــــ & & & & & & & & - & 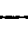 & & - & - & - & & & & 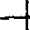 & - & 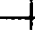 & $\ldots$ & & 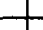 & - & & - \\
\hline & & & & & & & & & 8 & & & & & & . & $\rightarrow$ & & & & & & 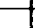 & 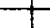 & & & & 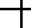 & \\
\hline & & & & & & & & & & & & & & & 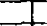 & 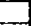 & & & & & & 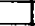 & - & & & & & \\
\hline \multirow{4}{*}{$105^{\circ}$} & & & & & & & & & $N$ & $y$ & - & 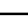 & & . & $\ldots$ & 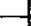 & - & 9 & & & . & 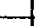 & - & & $\ldots$ & - & ـ. & $\ldots$ \\
\hline & & & & & & & & & & & & & & & & & & & & & & & - & & & & & \\
\hline & & & & & & & & & & 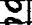 & - & & & & 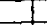 & 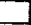 & & $\approx$ & & & 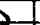 & & 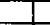 & & & & & \\
\hline & & 9 & & 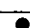 & & & & & 4 & 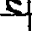 & & & & & - & - & & & & & & & ... & & & $\ldots$ & - & \\
\hline \multirow{4}{*}{$104^{\circ}$} & & & & 7 & & & & & & 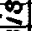 & & & & & & & & & & & & & & & & & & \\
\hline & & & & 4 & & & & 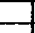 & 8 & 3 & $\ldots$ & & 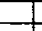 & $\square$ & $E$ & 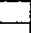 & $\square$ & 0 & & & 5 & 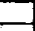 & $E$ & & 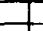 & $I$ & $I$ & ـ \\
\hline & & & & & & & & & & -1 & & 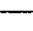 & & - & $\ldots$ & - & & & & & & & - & & & - & - & \\
\hline & & & 8 & - & & & & & 81 & & & & & & 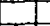 & 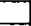 & 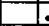 & & & & & & + & & 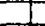 & 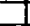 & 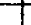 & \\
\hline \multirow{3}{*}{$103^{\circ}$} & & & - & - & $E$ & & & & 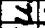 & $\Rightarrow$ & & & & & 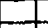 & 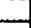 & & & & (), & & & & & & & & 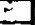 \\
\hline & & & & & & & & & 4 & o & & & & & & 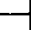 & & & & & & & & & & & - & \\
\hline & & & & & & & & & & 8 & & & & & 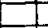 & & & & & & & & & & & 7 & 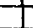 & \\
\hline \multirow{4}{*}{$102^{\circ}$} & & & & & & & & & 2 & 5 & & & & & $\ldots$ & & & & & & & & & & & & & \\
\hline & & & & - & & & & & & o. & & & & & & - & & & & & & & & & & & & \\
\hline & & & & & & & 1 & & & & & & & & & & & & & & & & & 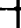 & & 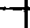 & - & \\
\hline & & & 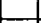 & & & & & 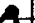 & & & - & & & & & & & & 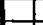 & & 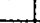 & & 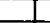 & & 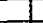 & 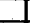 & 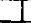 & \\
\hline \multirow{4}{*}{\multicolumn{2}{|c|}{$101^{\circ}$}} & & & & & & & & & & & & & & & & & & & & - & & 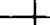 & & & $\ldots$ & $\ldots$ & \\
\hline & & 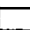 & & & & & & & & & & & & & & & & & & & & & & & & & & \\
\hline & & & & & & & & & & & & & & & & & 7 & & 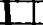 & & 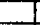 & & & & & & 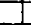 & 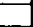 \\
\hline & & & & & & & & & & & & & & & & & & & 10 & & 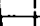 & & 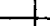 & & & . & L & \\
\hline \multirow{4}{*}{$100^{\circ}$} & & & & & & & & & & & & & & & & 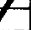 & & & & & & & & & & & & \\
\hline & & & & & - & & & & & & & & & & & - & & 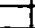 & + & & 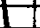 & 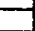 & 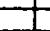 & & 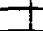 & 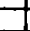 & 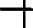 & \\
\hline & & & & & $\ldots$ & & & & 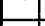 & & & & & & 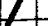 & 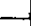 & & & & & & & & & & & & \\
\hline & & & - & - & + & - & & & & & - & & & & & $\rightarrow$ & & & & . & & & 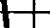 & & & & & \\
\hline \multirow{3}{*}{$99^{\circ}$} & & & & & & & & & & & & & & & & & & & & & & & & & & & & \\
\hline & & & & & & & & & & & & & & & & & & & & & & & & & & - & & \\
\hline & - & & & & & $\pi$ & & - & & & & - & - & & & . & & & 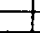 & - & & 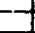 & 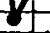 & & $y$ & 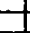 & 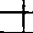 & \\
\hline \multirow{2}{*}{$\begin{array}{r}\text { Temperat. } \\
98^{\circ}\end{array}$} & & & & & & & & & & & & & & & & & 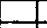 & & & & & 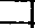 & & & & & 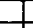 & \\
\hline & & & & & & & & 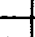 & & & & - & & & 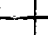 & & 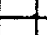 & & & & - & & - & & & 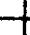 & & 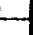 \\
\hline
\end{tabular}


Table III. Tabulation of sanitary personnel Harbin Hospital.

\begin{tabular}{|c|c|c|c|c|}
\hline \multicolumn{2}{|l|}{ Character } & $\begin{array}{l}\text { No. } \\
\text { employed }\end{array}$ & $\underset{\text { infected }}{\text { No. }}$ & $\begin{array}{l}\text { Per cent. } \\
\text { infected }\end{array}$ \\
\hline Doctors . & . & 8 & $\mathbf{l}$ & $12 \cdot 5$ \\
\hline Dressers . & • & 20 & 0 & 0.0 \\
\hline Sanitary coolies. & . & 13 & 5 & $38 \cdot 4$ \\
\hline Sanitary police & . & 10 & 1 & $10 \cdot 0$ \\
\hline Others (cook, etc.) & . & 3 & 0 & 0.0 \\
\hline Burial coolies & : & 18 & 7 & $38 \cdot 8$ \\
\hline
\end{tabular}

Table IV. Tabulation of our sanitary personnel in Dalainor*.

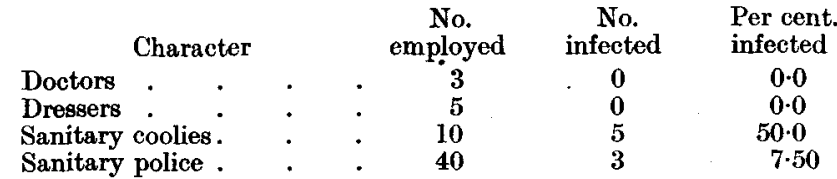

* The original sanitary personnel in Dalainor were vaccinated with plague vaccine, including six of the ten coolies (four of those vaccinated died) and all the policemen.

Table V.

Name. Liu Teng Yui (Chinese male). Age 32. Disease, Pneum. P. Survived 9 days.

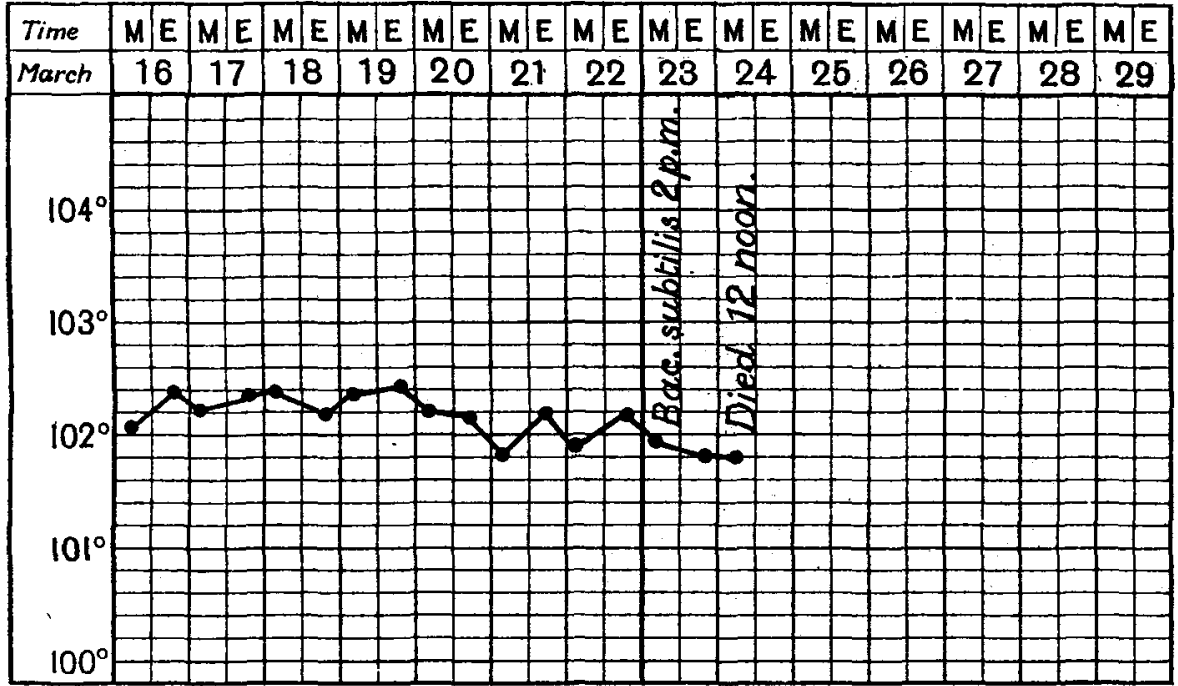




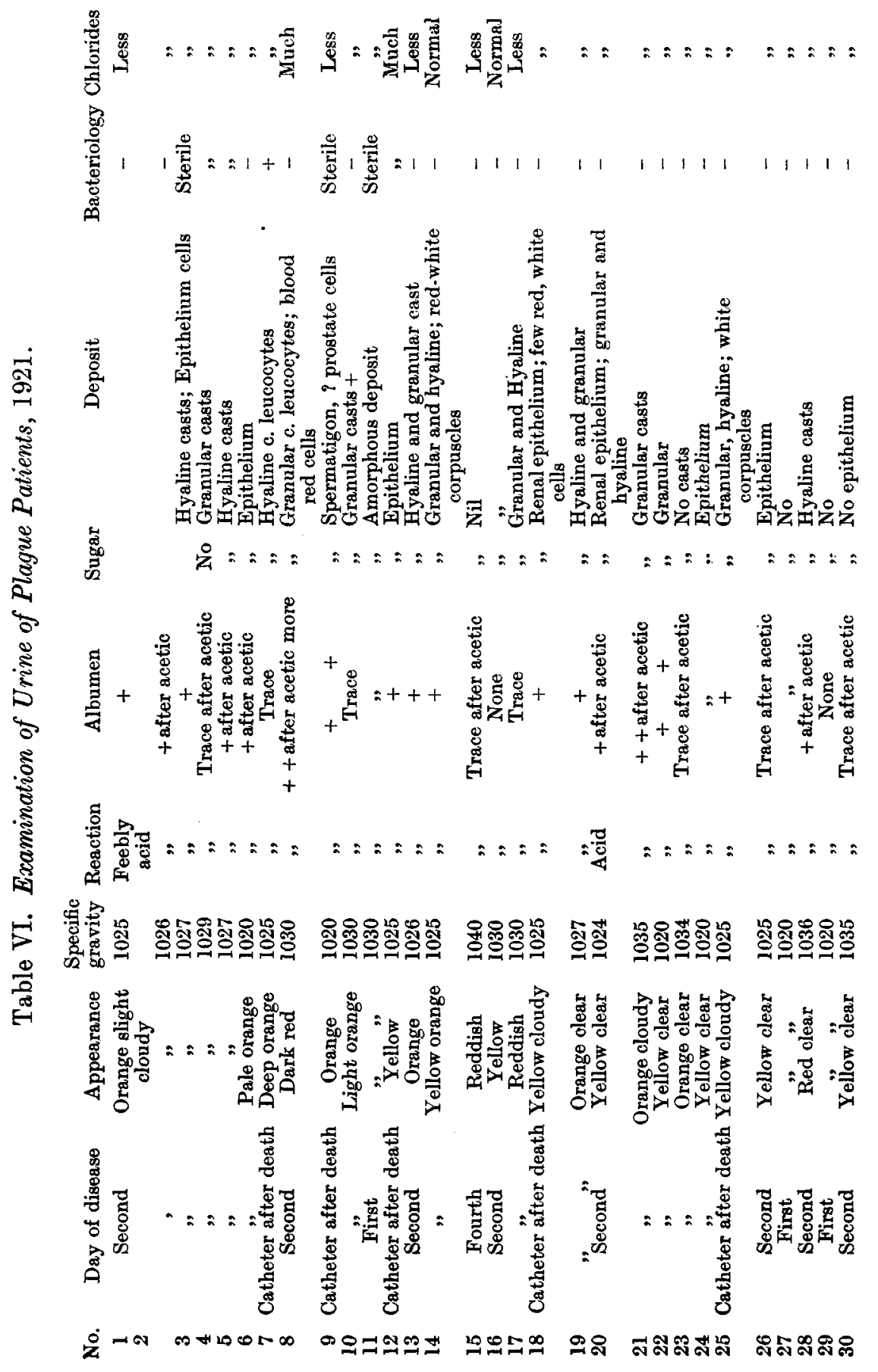

